\title{
Association between media attention and presentation of vaccination information on Canadian chiropractors' websites: a prospective mixed-methods cohort study
}

\author{
Yechan Kim MSc, Adeel M. Akhtar BHSc, Shane Natalwalla BHSc, Anna Goshua HBSc, \\ Kumanan Wilson MD MSc, Jason W. Busse DC PhD
}

Abstract

Background: Historically, some chiropractors have been critical of vaccination, and this has been the subject of recent media attention in Canada. We explored the association between media attention and public dissemination of vaccination information on Canadian chiropractors' websites.

Methods: In 2016, we identified all Canadian chiropractors' websites that provided information on vaccination by extracting details from the regulatory college website for each province using the search engine on their "find a chiropractor" page. We assessed the quality of information using the Web Resource Rating Tool (scores range from $0 \%$ [worst] to $100 \%$ [best]), determined whether vaccination was portrayed in a positive, neutral or negative manner, and conducted thematic analysis of vaccination content. We revisited all identified websites in 2019 to explore for changes to posted vaccination material.

Results: In July 2016, of 3733 chiropractic websites identified, 94 unique websites provided information on vaccination: 59 (63\%) gave negative messaging, $19(20 \%)$ were neutral and $16(17 \%)$ were positive. The quality of vaccination content on the websites was generally poor, with a median Web Resource Rating Tool score of $19 \%$. We identified 4 main themes: there are alternatives to vaccination, vaccines are harmful, evidence regarding vaccination and health policy regarding vaccination. From 2012 to 2016 , there was 1 Canadian newspaper story concerning antivaccination statements by chiropractors, whereas 51 news articles were published on this topic between 2017 and 2019. In April 2019, 45 (48\%) of the 94 websites we had identified in 2016 had removed all vaccination content or had been discontinued.

Interpretation: In 2016, a minority of Canadian chiropractors provided vaccination information on their websites, the majority of which portrayed vaccination negatively. After substantial national media attention, about half of all vaccination material on chiropractors' websites was removed within several years.

W ith about 9000 practitioners, chiropractic is Canada's third-largest regulated health care profession. ${ }^{1}$ Twelve percent of Canadians, largely adults, report having attended a chiropractor in the previous 12 months, predominantly for conservative management of low back and neck pain., ${ }^{2,3}$ The chiropractic profession comprises a range of providers, from evidence-based practitioners who focus on musculoskeletal complaints to traditional practitioners ("vitalists") who maintain historical beliefs that malpositioned spinal vertebrae ("subluxations") interfere with the nervous system, leading to a wide range of complaints and diseases. ${ }^{4}$ Historically, some prominent chiropractors have been extremely critical of vaccination, ${ }^{5}$ and some traditional practitioners maintain these attitudes. ${ }^{6,7}$

A survey of students attending the Canadian Memorial Chiropractic College showed that, in 2000, only $40 \%$ of graduating students endorsed vaccination. ${ }^{8}$ Readministration of the survey at the college in 2011/12 showed that $83 \%$ of graduating students were in favour of vaccines in general; 9 however, the repeat survey had a $33 \%$ response rate, versus $75 \%$ for the original administration. In a 2002 survey of all 643 licensed chiropractors in Alberta (response

Competing interests: Kumanan Wilson reports personal fees from CANImmunize, outside the submitted work. No other competing interests were declared.

This article has been peer reviewed.

Correspondence to: Jason Busse, bussejw@mcmaster.ca

CMAJ Open 2020. DOI:10.9778/cmajo.20190204 
rate $78 \%$ ), $27 \%$ reported that they advised their patients against vaccinating themselves or their children. ${ }^{10}$

Beginning in 2017, multiple national news stories highlighted antivaccination statements by Canadian chiropractors. We explored the prevalence and content of information regarding vaccination on Canadian chiropractors' websites and whether media attention was associated with any changes to such online material.

\section{Methods}

\section{Setting}

We conducted a prospective mixed-methods cohort study to explore the impact of media attention on vaccination content provided by Canadian chiropractors' websites between July 2016 and April 2019. We selected this period because from 2017 to 2019, there was considerable media attention regarding online antivaccination material by some Canadian chiropractors, which provided the opportunity for a natural experiment.

\section{Data sources}

We considered all Canadian chiropractors' websites that provided information on vaccination as of July 2016. We generated a database of all licensed Canadian chiropractors in June 2015 by extracting details from the regulatory college website for each province using the search engine on their "find a chiropractor" page and leaving all fields blank so that every member was listed. ${ }^{11-21}$ The Canadian Chiropractic Association's "find a chiro" search engine includes only the 10 provinces, and we could not find any online presence for chiropractic colleges in the Yukon Territory, the Northwest Territories or Nunavut.

For each licensed member, we performed a Google search with variations of his or her name, clinic name and location to determine which chiropractors maintained an Englishlanguage website. From July 2015 to March 2016, 2 reviewers (Y.K., A.M.A.) independently explored each unique website for vaccination content using the websites' search function with the root words vacc* and immun*. All identified websites with vaccination content were active as of July 22, 2016.

Two reviewers (Y.K., A.M.A.) independently evaluated the quality of all vaccination content using the Web Resource Rating Tool, ${ }^{22}$ a 13 -item tool that was developed in response to a 2012 systematic review that failed to identify any reliable and practical instrument focused on assessment of the quality of evidence used to support online information. ${ }^{22}$ The Web Resource Rating Tool assesses the quality of evidence (e.g., "Is the Web resource informed by published systematic reviews/meta-analyses?"), transparency (“Are peer-reviewed sources provided for each claim/recommendation?") and usability (e.g., "Is the information easy to follow?") of online health information and assigns an overall score ranging from $0 \%$ to $100 \%$, with higher scores representing better reporting quality, and a star rating, which ranges from 0 (lowest quality) to 5 (highest quality). The tool has been shown to be highly reliable, with an intraclass correlation coefficient for the total score of $0.99 .{ }^{22}$ The same pairs of reviewers classified each website as providing positive, negative or neutral information regarding vaccination. Any disagreements were resolved by discussion or by an arbitrator (J.W.B.) when necessary.

In April 2019, using the same review processes, we reviewed the same chiropractors' websites that we had identified in 2016 to determine any changes to their vaccination content following media attention to this issue (see media review below).

\section{Media review}

After we had abstracted material on vaccination from chiropractors' websites in 2016, there were multiple national news stories highlighting antivaccination statements by Canadian chiropractors, including members of regulatory colleges. ${ }^{23-32}$ We explored media trends on this topic by first searching Google, from Jan. 1, 2012, to Dec. 31, 2019, using the terms "chiropractor," "vaccination," "immunization" and "Canada" and limiting the search region to Canada. We then searched individual Canadian news sites (e.g., Globe and Mail, National Post, Toronto Star) with the same search terms. We reviewed each identified citation in full to confirm that the article discussed vaccination statements by Canadian chiropractors.

\section{Statistical analysis}

We generated frequencies for all collected data. Categoric data were reported as proportions and continuous data as means and standard deviations if normally distributed and as medians and interquartile ranges if not. We aggregated Web Resource Rating Tool scores for websites providing positive and neutral information and used an independent samples Mann-Whitney test to explore for differences between scores from websites providing negative portrayals. All comparisons were 2-tailed, and we set our level of significance at $p<0.05$. We performed all analyses using SPSS Statistics, version 25.0 (IBM Corp.).

\section{Thematic analysis}

We used thematic analysis to synthesize information regarding vaccination provided on chiropractors' websites into meaningful themes and subthemes. ${ }^{33,34}$ Two reviewers (Y.K., A.M.A.) used an open coding process to establish the primary categories of information from relevant material from each website, independently and in duplicate, and then connected the categories to derive main themes. Any disagreements were resolved by discussion. Five team members (Y.K., A.M.A., S.N., A.G., J.W.B.) then reviewed the results and confirmed the main themes and subthemes of our study findings.

\section{Ethics approval}

As per Article 2.2 (a) of the Tri-Council Policy Statement: Ethical Conduct for Research Involving Humans, research is exempt from research ethics board review if it relies exclusively on publicly available information that is legally accessible to the public and protected by law. ${ }^{35}$ 


\section{Results}

We identified 9131 registered Canadian chiropractors in the 10 provinces, who were associated with 3733 publicly available websites in 2016 (Figure 1, Table 1). Most websites (3590 [96.2\%]) did not mention vaccination or immunization. The remaining 143 websites $(3.8 \%)$ provided vaccination content, which reduced to 94 unique root domain websites (e.g., some chiropractors' websites contained multiple pages with information regarding vaccination).

The majority (59/94 [63\%]) of websites providing information on vaccination were negative in their messaging, 19 (20\%) were neutral, and 16 (17\%) were positive (Appendix 1, available at www.cmajopen.ca/content/8/2/E338/suppl/ DC1]). The quality of vaccination content was generally poor, with a median Web Resource Rating Tool score of $19 \%$ (interquartile range $14 \%-30 \%$ ). The quality did not differ based on whether the messaging was negative or not $(p=0.48)$ (Table 2).

\section{Thematic analysis}

We identified 4 main themes that emerged from our analysis of chiropractors' website vaccination content in 2016: there are effective alternatives to vaccination, vaccines are danger- ous, evidence regarding vaccination and health policy regarding vaccination (Table 3). Representative quotes are presented in Table 4 . Of the 16 websites with positive messaging, 15 (94\%) provided statements that vaccination had been established as effective. Among the 19 websites with neutral messaging, the most common statement (endorsed by 7 websites) was that the public should be provided with the current best evidence regarding vaccination in order to make informed decisions. Of the 59 websites with negative messaging, 51 $(86 \%)$ made claims that vaccination was dangerous.

\section{There are effective alternatives to vaccination}

Twenty-one websites indicated that chiropractic care was an alternative to vaccination. Another 14 websites suggested that naturopathic remedies could replace vaccination. Five websites promoted environmental improvements rather than vaccines as responsible for falling rates of vaccine-preventable diseases.

\section{Vaccines are dangerous}

Most websites portraying vaccination negatively included content that attributed severe adverse effects to vaccines or concluded that vaccines caused disease. Twenty-six websites made claims that vaccines contain harmful components, such as formaldehyde, aluminum and mercury.

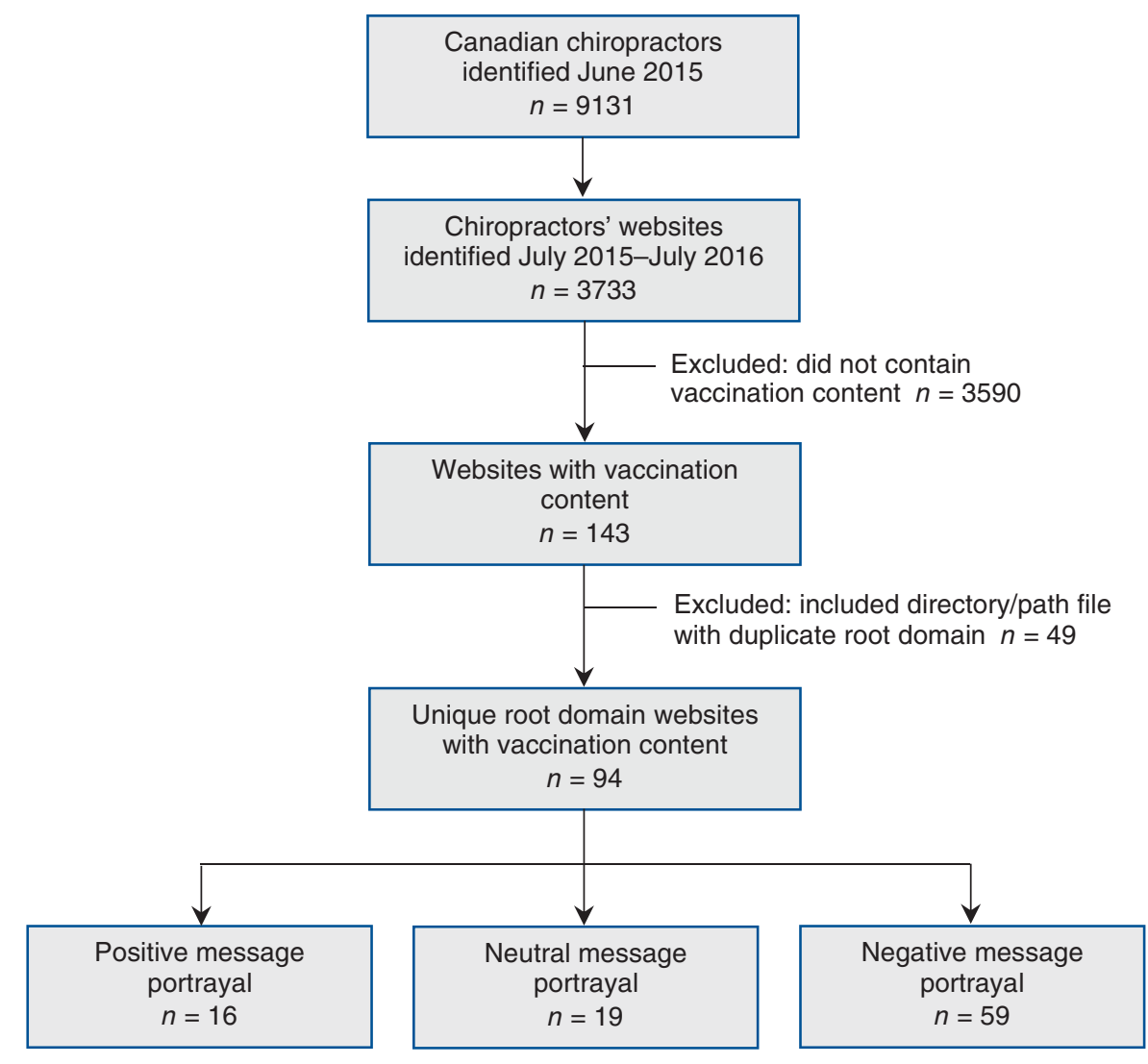

Figure 1: Flow diagram showing identification of Canadian chiropractors' websites with vaccination content. 
Table 1: Canadian chiropractors and English-language websites identified, by province, 2016

\begin{tabular}{|lccc|}
\hline Province & $\begin{array}{c}\text { No. (\%) of } \\
\text { chiropractors } \\
n=9131\end{array}$ & $\begin{array}{c}\text { No. (\%) of } \\
\text { chiropractic } \\
\text { websites } \\
n=3733\end{array}$ & $\begin{array}{c}\text { No. of chiropractic } \\
\text { websites with } \\
\text { vaccination content } \\
n=143\end{array}$ \\
\hline British Columbia & $803(8.8)$ & $285(7.6)$ & 7 \\
\hline Alberta & $726(8.0)$ & $302(8.1)$ & 5 \\
\hline Saskatchewan & $184(2.0)$ & $41(1.1)$ & 0 \\
\hline Manitoba & $319(3.5)$ & $132(3.5)$ & 9 \\
\hline Ontario & $5797(63.5)$ & $2461(65.9)$ & 106 \\
\hline Quebec & $1003(11.0)$ & $373(10.0)$ & 3 \\
\hline New Brunswick & $79(0.9)$ & $32(0.9)$ & 4 \\
\hline Nova Scotia & $148(1.6)$ & $76(2.0)$ & 0 \\
\hline Prince Edward Island & $7(0.1)$ & $5(0.1)$ & 2 \\
\hline Newfoundland and & $65(0.7)$ & $26(0.7)$ & \\
\hline Labrador & & & \\
\hline
\end{tabular}

\begin{tabular}{|c|c|c|c|}
\hline Component & $\begin{array}{c}\text { Positive } \\
\text { messaging } \\
n=16\end{array}$ & $\begin{array}{c}\text { Neutral } \\
\text { messaging } \\
n=19\end{array}$ & $\begin{array}{c}\text { Negative } \\
\text { messaging } \\
n=59\end{array}$ \\
\hline Median score* (IQR) & $18(12-19)$ & $22(14-39)$ & $21(14-32)$ \\
\hline \multicolumn{4}{|c|}{ Star rating, $†$ no. $(\%)$ of websites } \\
\hline 0 & $14(88)$ & $13(68)$ & $4(7)$ \\
\hline 1 & $1(6)$ & $5(26)$ & $34(58)$ \\
\hline 2 & $1(6)$ & $1(5)$ & $11(19)$ \\
\hline 3 & $0(0)$ & $0(0)$ & $9(15)$ \\
\hline 4 & $0(0)$ & $0(0)$ & $1(2)$ \\
\hline \multicolumn{4}{|c|}{$\begin{array}{l}\text { Note: IQR = interquartile range. } \\
{ }^{*} \text { Rated from } 0 \% \text { to } 100 \% \text {, with higher scores representing better reporting quality } \\
\text { †0= lowest quality, } 5=\text { highest quality. }\end{array}$} \\
\hline
\end{tabular}

\section{Evidence regarding vaccination}

Although many websites commented on the evidence for vaccination, most such sites claimed there was evidence of ineffectiveness. Some sites claimed the evidence was biased or was presented selectively to highlight potential benefits and downplay possible harms, or that evidence was conflicting and there was still uncertainty regarding the harms of vaccination.

Fifteen websites acknowledged that current evidence was supportive of vaccination, and these largely highlighted the position statement of the Canadian Chiropractic Association. ${ }^{36}$

\section{Health policy regarding vaccination}

A minority of websites (17) provided content regarding vaccination policy, with most claiming that the dangers of contracting certain vaccine-targeted infections had been exagger- ated, as had the effectiveness of some vaccines. The majority of such claims focused on influenza. Other subthemes were that industry was active in lobbying for health care policy that would benefit companies financially. Some sites claimed that mandatory vaccination was an infringement on personal liberty and provided links to the National Vaccine Information Center website, a leading source of antivaccination views ${ }^{37}$ and advised that the public should be better educated about vaccination in order to make informed decisions.

\section{Vaccination content following media attention}

We found only 1 Canadian newspaper article on chiropractic and vaccination from 2012 to 2016; however, from 2017 to 2019, there was a substantial increase in media stories regarding this topic, with 3 published in 2017, 21 in 2018, and 27 in 2019 (Figure 2).

In 2019, several years after Canadian media outlets began exploring antivaccination statements by some chiropractors, almost half of the websites we identified in $2016(45 / 94$ [48\%]) had been discontinued, or all content regarding vaccination had been removed. This predominantly involved sites that had published information portraying vaccination negatively; specifically, 33 (73\%) of 45 websites with negative messaging had been discontinued or their vaccination content removed. Of the 49 websites that were still active in 2019, 26 $(53 \%)$ provided negative information regarding vaccination (Appendix 2, available at www.cmajopen.ca/content/8/2/ E338/supp1/DC1).

\section{Interpretation}

In 2016, there were 3733 active websites maintained by Canadian chiropractors, $4 \%$ of which provided information regarding vaccination, the majority of which was negative. The quality of vaccination information was generally poor, and common themes were that there are effective alternatives to vaccination; vaccines are dangerous and can cause disease; the evidence on vaccination is often biased, conflicting or shows that vaccines are ineffective; and vaccination should not be mandatory. In 2019, following a large increase in national media attention to anti-vaccination statements by some Canadian chiropractors (including members of regulatory colleges), about half of chiropractors' websites providing information on vaccination were discontinued or the information regarding vaccination was removed.

The Canadian Chiropractic Association is supportive of vaccination and has published a statement that vaccination is not within the scope of practice for chiropractors, ${ }^{38}$ a position that is supported by 4 provincial regulatory colleges (Appendix 3, available at www.cmajopen.ca/content/8/2/ E338/suppl/DC1). However, the history of regulating information on vaccination by chiropractic colleges is complex. In 
Table 3: Themes and subthemes of vaccination content from chiropractors' websites in 2016

\begin{tabular}{|c|c|}
\hline Theme; subtheme & $\begin{array}{l}\text { Frequency of } \\
\text { endorsement }\end{array}$ \\
\hline \multicolumn{2}{|l|}{ There are effective alternatives to vaccination } \\
\hline Chiropractic can boost immunity & 21 \\
\hline Naturopathy can boost immunity & 14 \\
\hline $\begin{array}{l}\text { Better living conditions, improved sanitation and } \\
\text { improved nutrition are more effective than } \\
\text { vaccination }\end{array}$ & 5 \\
\hline \multicolumn{2}{|l|}{ Vaccines are dangerous } \\
\hline Cause severe adverse effects & 51 \\
\hline Have toxic components (e.g., mercury) & 26 \\
\hline Compromise immunity & 22 \\
\hline Cause autism & 14 \\
\hline Increase rates of various chronic diseases & 13 \\
\hline Cause Guillain-Barré syndrome & 9 \\
\hline Cause allergies & 8 \\
\hline Cause sudden infant death syndrome & 5 \\
\hline Cause asthma & 5 \\
\hline Increase risk of cancer & 4 \\
\hline Cause diabetes & 3 \\
\hline Cause attention deficit hyperactivity disorder & 2 \\
\hline Cause Crohn disease & 2 \\
\hline Cause shingles & 2 \\
\hline Increase risk of Alzheimer disease & 2 \\
\hline Cause ear infections & 1 \\
\hline \multicolumn{2}{|l|}{ Evidence regarding vaccination } \\
\hline $\begin{array}{l}\text { There is insufficient evidence to support } \\
\text { vaccination }\end{array}$ & 51 \\
\hline $\begin{array}{l}\text { Evidence in favour of vaccination is poor quality } \\
\text { and/or biased }\end{array}$ & 20 \\
\hline Evidence supports vaccination as effective & 15 \\
\hline Evidence for vaccination is conflicting & 7 \\
\hline $\begin{array}{l}\text { Evidence suggests that the harms of vaccination } \\
\text { outweigh the benefits }\end{array}$ & 2 \\
\hline \multicolumn{2}{|l|}{ Health policy regarding vaccination } \\
\hline $\begin{array}{l}\text { Dangers of vaccine-targeted diseases are } \\
\text { exaggerated by public health agencies and the } \\
\text { media }\end{array}$ & 17 \\
\hline Vaccines should not be mandatory & 15 \\
\hline $\begin{array}{l}\text { The Centers for Disease Control and Prevention } \\
\text { has important conflicts of interest regarding } \\
\text { vaccination }\end{array}$ & 11 \\
\hline $\begin{array}{l}\text { The public should be better educated about } \\
\text { vaccination }\end{array}$ & 7 \\
\hline
\end{tabular}

2004, following media attention on antivaccination statements by some chiropractors, the College of Chiropractors of Ontario (CCO) approved a Standard of Practice (S-015) requiring their members to refrain from discussing vaccina- tion with patients or the general public. Traditional chiropractors disagreed strongly with this standard, and some responded by seeking and acquiring elected positions on the CCO council. ${ }^{31,39}$

The change in leadership at the CCO appears to have had several consequences. According to some media reports, ${ }^{31,40}$ Standard of Practice S-015 was not enforced. In addition, the standard (which was later incorporated into Standard of Practice S-001) was revised on Feb. 8, 2011 to allow chiropractors to provide "balanced" information on vaccination to the public. ${ }^{39}$ Similar issues may have affected the British Columbia College of Chiropractors. ${ }^{41}$

Following recent media attention, the CCO Standard of Practice S-001 was amended in 2018 and 2019 to prohibit chiropractors from "providing information on vaccination on a member's website or social media account." ${ }^{\prime 2}$ On Dec. 2, 2019, the Canadian Chiropractic Association updated its position statement to state explicitly that vaccination and immunization are safe and effective public health practices for the prevention of infectious diseases. ${ }^{43}$

The Canadian media have drawn attention to antivaccination statements by chiropractors and seemingly had a large impact on curbing publication of such online material. Although this is laudable, chiropractic regulatory colleges should monitor chiropractors' websites and social media accounts for misleading information and enforce their Standards of Practice. It may also be helpful for medical and public health associations to work with Canadian chiropractic associations to collaborate on promotion of vaccination programs, ${ }^{4-46}$ as has been done by the American Public Health Association. ${ }^{47}$

\section{Limitations}

Strengths of our study include a rigorous approach to identify all practising chiropractors in Canada and any associated websites. In addition, rating of the quality of vaccine information, thematic analysis and the overall messaging (i.e., positive, neutral or negative) was conducted independently and in duplicate by pairs of reviewers to increase reliability. Our study is limited by the dynamic nature of the Internet, where websites can appear, disappear or be moved to other addresses overnight. We included only English-language websites, and our findings may not extend to websites in other languages. It is possible that our search of chiropractic college membership lists did not identify all practitioners; however, we identified 9131 chiropractors, and the Canadian Chiropractic Association advises there are about 9000 licensed chiropractors practising in Canada, ${ }^{1}$ which suggests that our results were comprehensive.

Our study was not designed to make causal attributions between media attention and removal of information regarding vaccination from chiropractors' websites, and other factors may have influenced these decisions. For example, on Mar. 14, 2019, the CCO issued a Professional Advisory instructing their members not to offer advice on vaccination; ${ }^{48}$ however, this advisory may also have been influenced by media attention, including negative media 
Table 4: Quotes illustrating themes

Theme

Representative quotes*

There are effective alternatives to vaccination$$
\text { , }
$$

People who receive regular chiropractic adjustments have immune system competency that is $200 \%$ greater than those who don't. (http://wellingtonchiropracticandwellnessgroup.com/health_ page.php?page=/dcnewsletter/jan11)

A healthy alternative to the conventional flu shot is a homeopathic natural immune boost shot. Homeopathy works by gently stimulating the body's innate ability to heal itself and there are virtually no side effects. (www.mypurebalance.ca/health-programs/natural-immune-boost-for-flu/) In light of these vital statistics, Palevsky finds it more reasonable to assume that the reason for the reduction in incidence and mortality rates of these diseases was predominantly due to the implementation of other public health strategies, including: clean water, better living conditions, improved sanitation and improved nutrition, than to the introduction of vaccines. (https:// dynamishealthcentre.com/articlesresources/vaccinations/points-of-doubt-regarding-vaccine -efficacy/)

Vaccines are dangerous

Vaccinations seem to, at least temporarily, increase one type of immunity while decreasing general immunity to many other forms of viruses and other ailments. (www.minoruchiropractic. com/article/2253.html)

There is a growing concern that one of the major threats to the development of healthy immune systems has been the increasing emphasis on artificial immunity through vaccines.... At the same time, rates of asthma, autism, allergies, digestive disorders, autoimmune diseases, cancer, and many other chronic conditions are also rising. Many scientists, chiropractors, medical doctors and parents have become alarmed that this massive volume and combination of inoculations is jeopardizing the long-term health of individuals and future generations. (http:// paramountfamilychiropractic.com/hylnet/clientapp/healtharticles.php?id=214)

A shocking research study published on May 4, 2011, shows a link between the number of vaccinations given to infants and an increase in infant mortality rate. (www.focuschiropractic.ca/ article/2177.html)

The final ingredient in a vaccine is a stabilizer like formaldehyde, a known cancer-causing agent for which there is no safe allowable limit for your body. (www.alconachiropractic.ca/hylnet/ clientapp/healtharticles.php?id=214)

Joseph Mercola, M.D., says that many authors have noted a direct correlation between the number of flu shots and the incidence of Alzheimer's, attributed to the aluminum and mercury in every flu shot. (http://nrfc.ca/187/the-flu-shot/)

Evidence regarding Mass vaccination was halted in Third World countries because it didn't work. (http://chetday. vaccination com/smallpoxepidemic.htm)

Just like all vaccines there are side-effects with the flu shot. The [Centres for Disease Control and Prevention] and other organizations would have you overlook them for the supposed benefit of being inoculated against the flu. (http://nrfc.ca/187/the-flu-shot/)

Research linking autism to vaccines is conflicting. Thimerosal, a preservative in vaccines that is 49 percent ethyl mercury, was removed from childhood immunizations in 2001. However, some flu vaccines may still contain thimerosal. (www.edwinlauchiropractic.com/newsletters/OHU -2009\%2001-12.pdf)

The Canadian Chiropractic Association recognizes that vaccination and immunization are established public health practices in the prevention of infectious diseases. (www.physiomed.ca/ blog/general-tips/surviving-cold-flu-season/)

Health policy regarding vaccination
The flu vaccine may not give the benefits that were previously advertised. (www. focuschiropractic.ca/article/1793.html)

A February 11, 2007 story appearing in the Washington Post and no less than 72 different news publications has exposed the fact that a major drug company, Merck \& Co. is behind the large lobbying effort to have 18 states pass laws making their vaccine required for 6 th grade girls. If these laws pass, Merck, which last year showed revenues of $\$ 22.6$ billion, stands to earn hundreds of millions of dollars. (www.robieatspringgardenchiropractic.com/article/1592.html) As more vaccines have been recommended and mandated by government health officials, [the National Vaccine Information Center] is receiving more reports from Americans describing how they are being harassed for trying to make informed vaccine choices for themselves and their children. (www.nvic.org/reporting-systems.aspx)

Vaccinations are a controversial subject and it's imperative to inform yourself before deciding whether or not to vaccinate yourself or those under your care. (https://dynamishealthcentre. com/articlesresources/vaccinations/)

*These quotes were active on chiropractors' websites as of July 2016. 


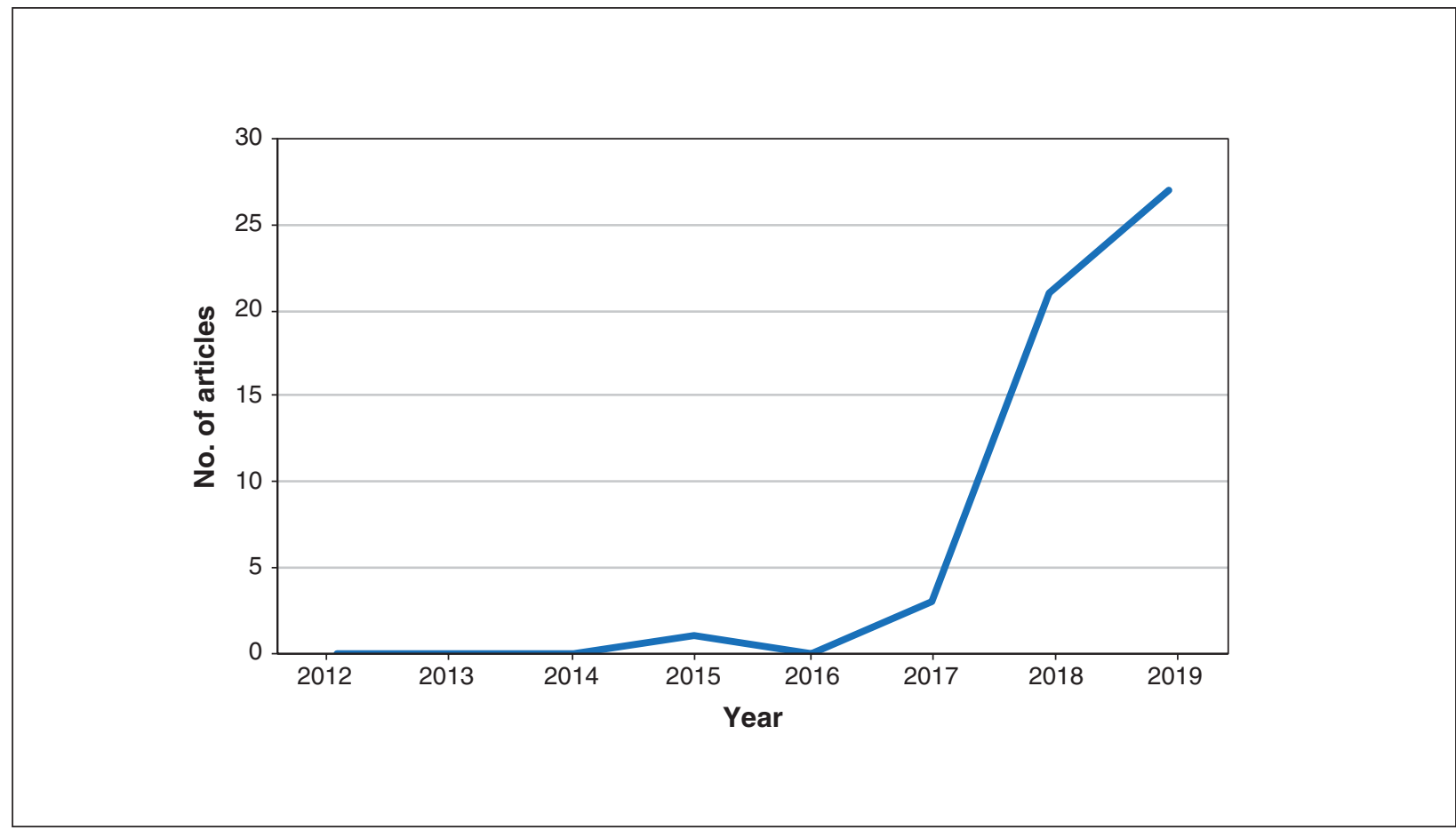

Figure 2: Frequency of Canadian news articles regarding vaccination statements by chiropractors, 2012-2019.

attention specifically targeting antivaccination statements made by $\mathrm{CCO}$ council members in executive positions. ${ }^{32}$

Finally, our study captured only vaccine information on chiropractors' websites, which does not represent the frequency of discussion with patients on this topic.

\section{Conclusion}

Although a minority of Canadian chiropractors provided vaccination content on their websites, the quality of information was often poor, and most sites did not explicitly support vaccination. Following national media attention, almost half of all such online material was removed.

\section{References}

1. Quick facts. Toronto: Canadian Chiropractic Association. Available: www. chiropractic.ca/media-centre/quick-facts/ (accessed 2020 Feb. 8).

2. Beliveau PJH, Wong JJ, Sutton DA, et al. The chiropractic profession: a scoping review of utilization rates, reasons for seeking care, patient profiles, and care provided. Chiropr Man Therap 2017;25:35.

3. Mior S, Wong J, Sutton D, et al. Understanding patient profiles and characteristics of current chiropractic practice: a cross-sectional Ontario Chiropractic Observation and Analysis STudy (O-COAST). BMF Open 2019;9:e029851.

4. Leboeuf-Yde C, Innes SI, Young KJ, et al. Chiropractic, one big unhappy family: Better together or apart? Chiropr Man Therap 2019;27:4.

5. Campbell JB, Busse JW, Injeyan HS. Chiropractors and vaccination: a historical perspective. Pediatrics 2000;105:E43.

6. Busse JW, Morgan L, Campbell JB. Chiropractic antivaccination arguments. 7 Manipulative Physiol Ther 2005;28:367-73.

7. McGregor M, Puhl AA, Reinhart C, et al. Differentiating intraprofessional attitudes toward paradigms in health care delivery among chiropractic factions: results from a randomly sampled survey. BMC Complement Altern Med 2014;14:51.

8. Busse JW, Kulkarni AV, Campbell JB, et al. Attitudes toward vaccination: a survey of Canadian chiropractic students. CMA7 2002;166:1531-4.

9. Lameris M, Schmidt C, Gleberzon B, et al. Attitudes toward vaccination: a cross-sectional survey of students at the Canadian Memorial Chiropractic College. 7 Can Chiropr Assoc 2013;57:214-20.
10. Russell ML, Injeyan HS, Verhoef MJ, et al. Beliefs and behaviours: understanding chiropractors and immunization. Vaccine 2004;23:372-9.

11. Find a chiro. Toronto: Canadian Chiropractic Association. Available: www. chiropractic.ca/about-chiropractic/find-a-chiro/ (accessed 2020 Feb. 8).

12. Searchable online public register. Toronto: College of Chiropractors of Ontario. Available: https://onlineservice.cco.on.ca/webs/cco/register/?t=1 (accessed 2020 Feb. 8).

13. Find a chiropractor. Vancouver: College of Chiropractors of British Columbia. Available: https://registry.chirobc.com/Search/Search?chkAcceptTerms=on (accessed 2020 Feb. 8).

14. Find a chiro. Anjou (QC): Association des chiropraticiens du Québec. Available: www.chiropratique.com/en/find-a-chiropractor/ (accessed 2020 Feb. 8).

15. Find a Manitoba chiropractor. Winnipeg: Manitoba Chiropractors Association. Available: https://manitobachiropractors.ca/find-an-mb-chiropractor/ (accessed 2020 Feb. 8).

16. Find a chiropractor. St. John's: Newfoundland and Labrador Chiropractic Association. Available: http://nlchiropractic.ca/chiropractors/find-a-chiropractor/ (accessed 2020 Feb. 8)

17. Find a chiropractor. Halifax: Nova Scotia College of Chiropractors. Available: www.knowyourback.ca/find-a-chiropractor/ (accessed 2020 Feb 8).

18. Find a chiro. Charlottetown: Council of the Prince Edward Island Chiropractic Association. Available: www.chiropractic.ca/about-chiropractic/find-a -chiro/?Province=PE (accessed 2020 Feb. 8).

19. Using our search tool: find a chiropractor near you. Regina: Chiropractors' Association of Saskatchewan. Available: https://saskchiro.ca/find-a-chiropractor/ (accessed 2020 Feb. 8).

20. Find a chiropractor in Alberta. Edmonton: Alberta College and Association of Chiropractors. Available: https://albertachiro.com/find-a-chiro (accessed 2020 Feb. 8).

21. Find a chiropractor. Moncton (NB): New Brunswick Chiropractors Association. Available: https://nbchiropractic.ca/find-a-chiropractor/ (accessed 2020 Feb. 8).

22. Dobbins M, Watson S, Read K, et al. A tool that assesses the evidence, transparency, and usability of online health information: development and reliability assessment. 7MIR Aging 2018;1:e3.

23. Marcoux J, Pedersen K, Nicholson K. Advertising by some Manitoba chiropractors undermines public health, expert says. CBC News 2017 Mar. 20, 2017; updated 2017 Apr. 20. Available: www.cbc.ca/news/canada/manitoba/ advertising-manitoba-chiropractors-1.4030574 (accessed 2020 Feb. 8).

24. Marcoux J, Nicholson K. Too early to say if disciplinary action needed for questionable ads: chiropractors association. CBC News 2017 Mar. 22. Available: www.cbc.ca/news/canada/manitoba/manitoba-chiropractors-association-review -ads-1.4035366 (accessed 2020 Feb. 8).

25. Kubinec VL, Nicholson K. Some chiropractors forced to adjust websites after association cracks down on health messaging. CBC News 2018 Jan. 5. Available: 
www.cbc.ca/news/canada/manitoba/chiropractors-advertising-claims-crackdown -1.4473992 (accessed 2020 Feb. 8)

26. Lindsay B. Province directs removal of anti-vaccine posts that broke B.C. rules for chiropractors. CBC News 2018 May 2; updated 2018 May 2. Available: www.cbc.ca/news/canada/british-columbia/province-directs-removal-of -anti-vaccine-posts-that-broke-b-c-rules-for-chiropractors-1.4645068 (accessed 2020 Feb. 8).

27. Doucette K. Regulator investigating Halifax chiropractor's posts on vaccination. CTV Newus 2018 May 25. Available: https://atlantic.ctvnews.ca/regulator -investigating-halifax-chiropractor-s-posts-on-vaccination-1.3945068 (accessed 2020 Feb. 8).

28. Young L. Here's what naturopaths and chiropractors shouldn't be advising you about. Global News 2018 June 2. Available: https://globalnews.ca/news/ 4248401/naturopath-chiropractor-advice-vaccination/ (accessed 2020 Feb. 8).

29. Lindsay B. There's an epidemic of bogus health claims online, and no easy cure: distrust of institutions fuels medical myths, and social media only reinforces false claims. CBC News 2018 June 9. Available: www.cbc.ca/news/ canada/british-columbia/there-s-an-epidemic-of-bogus-health-claims-online -and-no-easy-cure-1.4695898 (accessed 2020 Feb. 8).

30. Campbell F. Anti-vaxxing statements lead to Oxford Chiropractors clinic closure. The Chronicle Herald [Halifax] 2018 Oct. 19. Available: www. thechronicleherald.ca/news/local/anti-vaxxing-statements-lead-to-oxford -chiropractors-clinic-closure-251956/ (accessed 2020 Feb. 8).

31. Benedetti P, MacPhail W. Chiropractors at a crossroads: the fight for evidencebased treatment and a profession's reputation. Globe and Mail [Toronto]. Available: www.theglobeandmail.com/canada/article-chiropractors-at-a-crossroads -the-fight-for-evidence-based-treatment/ (accessed 2020 Feb. 8)

32. MacPhail W, Benedetti P. Three senior members of the council that regulates Ontario chiropractors have made anti-vaccination statements. National Post [Toronto]. Available: https://nationalpost.com/news/college-of-chiropractors -of-ontario-anti-vaccine (accessed 2020 Feb. 8).

33. Braun V, Clarke V. Using thematic analysis in psychology. Qual Res Psychol 2006;3:77-101

34. Vaismoradi M, Turunen H, Bondas T. Content analysis and thematic analysis: implications for conducting a qualitative descriptive study. Nurs Health Sci 2013;15:398-405.

35. Canadian Institutes of Health Research; Natural Sciences and Engineering Research Council of Canada; Social Sciences and Humanities Research Council of Canada. Tri-Council Policy Statement: ethical conduct for researcb involving bumans. Ottawa: Secretariat on Responsible Conduct of Research; 2014.

36. Policy manual, motion 2139/93. Toronto: Canadian Chiropractic Association; 1993.

37. Bradshaw AS, Treise D, Shelton SS, et al. Propagandizing anti-vaccination: Analysis of Vaccines Revealed documentary series. Vaccine 2020;38:2058-69.

38. Vaccination and immunization. Toronto: Canadian Chiropractic Association. Available: www.chiropractic.ca/about-cca/code-of-ethics/vaccination -immunization/ (accessed 2019 Nov. 8)

39. Gleberzon B, Lameris M, Schmidt C, et al. On vaccination \& chiropractic: when ideology, history, perception, politics and jurisprudence collide. 7 Can Chiropr Assoc 2013;57:205-13

40. Mesley W. The debate over childhood vaccination. The National (CBC) 2011 Jan. 26.
41. Lindsay B. Ministry considered options for handling 'dysfunctional' chiropractors college after CBC report, FOI shows. CBC News 2018 Mar. 18 Available: www.cbc.ca/news/canada/british-columbia/chiropractor-college -health-ministry-complaint-vaccination-1.5058659 (accessed 2020 Feb. 8).

42. Standard of Practice S-001. Toronto: College of Chiropractors of Ontario 2019. Available: www.cco.on.ca/wp-content/uploads/2019/06/S-001April30 2019.pdf (accessed 2019 Nov. 8).

43. Vaccination and immunization resources. Toronto: Canadian Chiropractic Association. Available: www.chiropractic.ca/vaccination-and-immunization -resources/ (accessed 2020 Feb. 8).

44. Busse JW, Wilson K, Campbell JB. Attitudes towards vaccination among chiropractic and naturopathic students. Vaccine 2008;26:6237-43.

45. McMurtry A, Wilson K, Clarkin C, et al. The development of vaccination perspectives among chiropractic, naturopathic and medical students: a case study of professional enculturation. Adv Health Sci Educ Theory Pract 2015;20: 1291-302.

46. Johnson C, Baird R, Dougherty PE, et al. Chiropractic and public health: current state and future vision. 7 Manipulative Physiol Ther 2008;31:397-410.

47. Chiropractic health care. Washington: American Public Health Association. Available: www.apha.org/apha-communities/member-sections/chiropractic -health-care (accessed 2020 Feb. 8).

48. Professional advisory on vaccination and immunization. College of Chiropractors of Ontario; 2019. Available: www.cco.on.ca/wp-content/uploads/2019/03/ Professional-Advisory-Vaccination-March142019.pdf (accessed 2020 Feb. 8).

Affiliations: Faculty of Medicine (Kim), University of Western Ontario, London, Ont.; Departments of Medical Sciences (Kim), Health Sciences (Akhtar), Anesthesia (Busse) and Health Research Methods, Evidence \& Impact (Busse), McMaster University, Hamilton, Ont.; Faculty of Medicine (Akhtar), Royal College of Surgeons in Ireland, Dublin, Ireland; Faculty of Medicine (Natalwalla), University of Toronto, Toronto, Ont.; School of Medicine (Goshua), Stanford University, Stanford, Calif.; Clinical Epidemiology Program (Wilson), Department of Medicine, Ottawa Hospital; Bruyère Research Institute (Wilson), Ottawa, Ont.

Contributors: Yechan Kim, Adeel Akhtar, Shane Natalwalla and Anna Goshua acquired and analyzed the data. Yechan Kim and Adeel Akhtar drafted the manuscript. All of the authors contributed to the conception and design of the study, interpreted the data, revised the manuscript critically for important intellectual content, approved the final version to be published and agreed to be accountable for all aspects of the work. Yechan Kim and Adeel Akhtar contributed equally to this work.

Data sharing: The data are available on request from the corresponding author, Jason Busse, bussejw@mcmaster.ca.

Supplemental information: For reviewer comments and the original submission of this manuscript, please see www.cmajopen.ca/content $/ 8 / 2 /$ E338/suppl/DC1. 